\title{
CONTEMPLEM! EIS O COMUNICADOR DA NORMA
}

\section{Ana Elisa Spaolonzi Queiroz Assis ${ }^{1}$}

\section{Resumo}

O objetivo do artigo é problematizar o mito do juiz enquanto protagonista nos processos de judicialização das políticas públicas, para apresentar o comunicador da norma como real ator principal. Por meio da problematização comparada tanto dos sistemas de civil lawe common law como da atuação do magistrado nestes sistemas, seguido de breve conceituação dos termos "controle judicial", "judicialização" e "ativismo judicial" visa demonstrar que suas características são previamente determinadas nas petições iniciais, bem como apresentar a atuação coadjuvante do juiz e o alto grau de responsabilidade do comunicador da norma, a quem conceituamos e definimos seu papel, em especial, quando se trata da discussão de problemas públicos junto ao Poder Judiciário. Sem a pretensão de propor soluções, finalizamos com uma reflexão acerca do silêncio em torno deste real protagonismo.

Palavras chave: Judicialização; Comunicador da Norma; Políticas Públicas; Sistemas Jurídicos.

\section{INTRODUÇÃO}

Se a imagem do juiz está intimamente relacionada com uma figura que decide a vida das pessoas, talvez seja necessário oferecer uma alternativa a essa acepção corrente da sociedade brasileira. Isto não significa diminuir a competência de atuação do magistrado, mas ponderar que há outros atores envolvidos nas decisões judiciais.

Em que pese o fato de que este artigo não será escrito à luz da filosofia de Friedrich Nietzsche (18441900), sua trajetória e obra propiciam a construção de uma analogia, de forma propedêutica a esse texto, quando em relação à morte de Deus. É no parágrafo 125 de A Gaia Ciência (Die fröhliche Wissenschaft) que o filósofo alemão faz considerações em torno do homem furioso, traduzido em língua portuguesa por homem louco (Der tolle Mensch) (NIETZSCHE, 2001), que disse: "[ ... ] 'Para onde foi Deus', gritou ele, 'já lhes direi! ' Nós o

\footnotetext{
${ }^{1}$ Doutorado em Educação (PUC-Campinas e UNICAMP). Professora da Faculdade de Educação da UNICAMP, Coordenadora Associada do Curso de Pedagogia (gestão 2016-2017), pesquisadora do Laboratório de Políticas Públicas e Planejamento Educacional - LaPPlanE, bem como do Laboratório de Gestão Educacional - LAGE e do Laboratório de Ensinagem de Redes Técnicas e Sustentabilidade Socioambiental - FLUXUS, este, da Faculdade de Engenharia Civil, Arquitetura e Urbanismo da UNICAMP. Professora convidada da Unidad de Pedagogía Universitária y Didactica del Derecho da Universidad de Chile. Email: anaelisasqa@gmail.com
} 
matamos - vocês e eu. Somos todos seus assassinos! ” [... ] Deus está morto! Deus continua morto! E nós o matamos! Como nos consolar, a nós, assassinos entre os assassinos? [... ]” (NIETZSCHE, 2001, p. 147)2.

Nessa perspectiva, e se declarássemos, fazendo uma analogia com Nietzsche (2001), que o juiz está morto? E, ao contrário do filósofo, o fizéssemos não porque esta figura perdeu sua influência no cotidiano da política (policy), mas para evitar que o crédito a ele concedido do sucesso ou do fracasso de uma ação judicial, seja demasiado; como uma aceleração da compreensão necessária ao papel que realmente lhe cabe. Afinal de contas, "o importante não é a notícia de que Deus está morto, mas o tempo que ela gasta para dar seus frutos" (DELEUZE \& GUATARI, 2010 p. 145/146).

Os frutos, não são as consequências de compreender a morte do juiz, mas da percepção de que sua morte, não tem qualquer consequência; em outras palavras, ainda que a figura central nas discussões acerca da relação entre o Poder Judiciário e as políticas públicas seja o juiz (ASSIS, 2015; 2012; APPIO, 2009; CEPEDA RODRÍGUEZ, 2012; KOERNER, 2013), no sistema jurídico brasileiro ele é coadjuvante, e não ator principal como se quer crer.

Para que possamos problematizar, ao longo deste trabalho, o mito de que o juiz é o ator principal quando as políticas públicas se relacionam com o Poder Judiciário iremos, primeiramente, contrapor os sistemas de civil lawe common law, bem como o papel dos juízes em cada um destes sistemas, haja vista grande parte da literatura sobre o tema transitar entre países anglo-saxões e países romano-germânicos sem uma reflexão de replicação ${ }^{3}$. Em seguida, vamos diferenciar controle judicial, ativismo judicial e judicialização, a fim de demonstrar que suas características são previamente determinadas pelas petições iniciais ${ }^{4}$ e pelos objetos de ação ${ }^{5}$ quando se trata do sistema de civil lawbrasileiro.

Por fim, uma vez que o juiz tenha saído do papel de ator protagonista e os parâmetros conceituais acerca da temática estejam estabelecidos, definir quem é o comunicador da norma e o seu papel nas relações entre o Poder Judiciário e as políticas públicas.

\footnotetext{
${ }^{2}$ No original se lê: "Wohin ist Gott?", rief er, 'ich will es euch sagen! Wir haben ihn gotötet - ihr und ich! Wir alle sind seine Mörder! [...] Gott ist tot! Gott bleibt tot! Und wir haben ihn getötet. Wie trösten wir uns, die Mörder aller Mörder? [ ... ]". (NIETZSCHE, 1999, p. 120).

${ }^{3}$ A dialética da complementariedade (REALE, 2002) nos permite pensar em replicação de conceitos e teorias na área de estudos sobre políticas públicas, numa perspectiva de Tecnologia Social, vale dizer, de forma a considerar as diferenças existentes entre as condições de quem trouxe a teoria/conceito e as condições de quem e onde os utiliza (RUTKOWSKI et. al., 2010).

${ }^{4}$ Documento que dá origem ao processo diante do Poder Judiciário, e na qual devem constar determinadas informações, como os fatos, os fundamentos jurídicos, provas pedidos, entre outros (art. 319) (BRASIL, 2015)

${ }^{5}$ É a identificação do bem que precisa de proteção, podendo ser um bem material ou jurídico, como por exemplo, o direito à educação.
} 


\section{QUANDO EM ROMA, FAÇA COMO OS ROMANOS!}

Ainda que atualmente possamos falar na existência de dois principais sistemas jurídicos, a saber: common lawe civil law', Nogueira (2013) nos chama a atenção para o seguinte fator:

Estabelecer as diferenças entre as duas famílias não é tarefa fácil. Essa afirmação decorre da (cada vez maior) aproximação entre as duas famílias, fenômeno detectado quase que pela totalidade da doutrina mundial. A separação que os historiadores identificam ter ocorrido no século XIII parece estar diminuindo, demonstrando que a evolução do direito é um ciclo fechado. (...). De qualquer forma a aproximação não se limita ao fato de estarmos nos valendo de institutos que têm origem na common law, sendo certamente mais ampla. $\mathrm{O}$ fato é que civil law e common law se aproximam cada vez mais. A razão? A globalização é apontada como a causa principal (p. 33).

Todavia, tal aproximação é um processo e não um fato consumado, o que justifica compreender as diferenças entre estes sistemas, não só para que o uso das produções científicas de cada localidade não passe ao largo das particularidades inerentes a cada um deles, mas para que neste percurso possamos, inclusive, identificar os melhores núcleos de aproximação quando se trata da discussão da relação entre políticas públicas e Poder Judiciário.

Em países com procedência anglo-saxã, prevalece o sistema jurídico do common law ou direito consuetudinário, originário na Inglaterra no século IX sofrendo modificações até o século XV para estabelecer-se como o conhecemos. A base legal deste sistema resta nos costumes e tradições de determinada população, os quais criam neste ambiente alguns princípios a serem seguidos, fato que ao longo dos séculos foi construindo precedentes judiciais (RÁO, 1999; DAVID, 1996).

Os precedentes judicias são o fundamento do direito consuetudinário, e podem ser entendidos como um conjunto de manifestações, provindas de diferentes juízes, acerca de fatos concretos, objetivando resolver os problemas apresentados ao Poder Judiciário (NOGUEIRA, 2013). Sendo assim, não é de um conjunto de leis que se extrai uma regra de direito, mas da análise dos precedentes a fim de criar uma jurisprudência, que nada mais é do que a reiteração de decisões jurídicas com compreensões similares sobre o mesmo objeto em diferentes casos. Em outras palavras, o que dá segurança jurídica ${ }^{7}$ na common law, é basear as decisões nos precedentes judiciais.

Isso não significa dizer que, porque o sistema se mantém ao longo tempo, acaba sendo retrógrado, pois baseia-se em um processo histórico secular; é preciso compreender que ao firmar-se em princípios, ao invés de

\footnotetext{
${ }^{6}$ Para que seja possível uma comparação baseada em conduções processuais, usaremos como base o common law norteamericano e o civil law brasileiro para discutir os pormenores de cada sistema, o que, entendemos, não inviabiliza a compreensão da existência de diferenças significativas que influenciam na forma de assumir a participação do magistrado em cada sistema.

${ }^{7}$ A segurança jurídica pode ser entendida como aquilo" que garante aos cidadãos a manutenção da linearidade e igualdade nas decisões judiciais em casos semelhantes, bem como a certeza de que o que foi decidido não será mudado” (ASSIS, 2012 p.20). 
regras, mantém a identificação da palavra ${ }^{8}$, mas são capazes de rever o significado de acordo com os novos costumes e tradições.

Pensemos no Princípio da Igualdade enquanto palavra que materializa pensamento abstrato sobre um aspecto das relações entre seres humanos. Muito embora o mesmo estivesse disposto na Declaração dos Direitos do Homem e do Cidadão de 1793, não se pode dizer que possui o mesmo significado (conteúdo) de quando fora colocado na Declaração Universal dos Direitos Humanos de 1948. Bem como, já não podemos afirmar que seu significado na segunda metade do século XX corresponde ao do século XXI.

Note que o princípio norteador da discussão permanece o mesmo. No nosso exemplo, é a Igualdade que será evidenciada nos casos que envolvam relações sociais; mas sua abrangência, sua aplicabilidade, sofreu modificações ao longo do tempo, o que não significa abandono, apenas atribuição de diferentes aspectos.

Podemos pensar, então, que se o significado atribuído ao signo tem peso na aplicabilidade dos princípios, o juiz ocupa um lugar de destaque no processo judicial e não há que se falar em sua morte. Todavia, Andrighi (1994) nos esclarece que durante o processo judicial no common law norte americano, o juiz é um ator passivo, pois não tem qualquer participação na busca pela verdade real, ou seja, na condução e no direcionamento da busca de provas sobre a lide, que fica a cargo das partes envolvidas.

Neste contexto, resta ao juiz manifestação no momento da decisão, cujo protagonismo the pode ser roubado acaso as partes optem por um julgamento pelo Júri e não por um julgamento singular, onde se manifestaria de imediato após a apresentação das provas.

Sendo num formato ou noutro (Júri ou Julgamento Singular) sua atuação é secundária. No caso de um julgamento singular, só poderá decidir dentro das provas que as partes the apresentaram, não há espaço para solicitar outras/novas provas, pois não participou do processo de descobrimento (discovery), é como se as partes colocassem um antolho no juiz limitando seu universo para a tomada da decisão. Já no caso do Júri, a decisão é de responsabilidade do grupo que deverá ser convencido pelas partes diante das regras estabelecidas e arbitradas pelo juiz e pelos procedimentos processuais a ela inerentes.

Atuação bastante diferente tem o juiz no sistema de civil law. O Brasil, assim como outros países de origem germânico-romana, tem raízes no Direito Romano, o que significa dizer que sua influência tem origem na codificação das leis, fato que marcou as doutrinas francesa e alemã no século XIX (MERRYMAN \& PÉREZPERDOMO, 2009) Neste sistema, a fonte primária do direito é a lei, já os costumes e as jurisprudências são fontes secundárias (REALE, 2002).

\footnotetext{
${ }^{8}$ Aqui entendida como representação sonora e/ou escrita de uma ideia, haja vista não ser objetivo deste trabalho tocar nas discussões linguísticas acerca de signo, significante e significado, mas tão somente traçar uma exposição exemplificativa para o tema do common law.
} 
As jurisprudências e os costumes não são extirpados do civil law, mas tão somente ocupam lugar secundário diante das codificações. Tomando como exemplo o sistema de civil law brasileiro, as jurisprudências são utilizadas dentro das ações judicias como formas de demonstrar que o argumento apresentado tem sido acatado em outras situações e lugares, funcionam como as citações diretas e indiretas num trabalho científico.

No caso dos costumes, temos exemplo tanto daqueles que nunca foram codificados, mas são legítimos diante da concessão de direitos, quanto daqueles que foram codificados e devido à mudança de comportamento da sociedade, foram retirados do ordenamento jurídico.

Na primeira situação, podemos citar a fila, que nunca foi codificada, mas que dá a garantia do atendimento na sequência estabelecida diante da acomodação dos indivíduos. Todavia, esse costume, deve submeter-se às leis que regulam os casos de preferência para idosos, doadores, mães com crianças de colo, gestantes e pessoas com deficiência; talvez, acaso o respeito a estas minorias fosse um costume da população, não houvesse a necessidade de codificá-los.

Já na segunda situação, os que foram codificados, mas retirados do ordenamento, temos o caso do crime de rapto, antigo artigo 219 do Código Penal (BRASIL, 1940) inexistente desde 2005 no Brasil. Tal crime estava tipificado como "Raptar mulher honesta, mediante violência, grave ameaça ou fraude, para fim libidinoso", sua revogação não impediu que o rapto de pessoas com uso de violência com fins libidinosos fosse penalizado, já que isto tornou-se agravante do crime de sequestro e cárcere privado previstos no artigo 148 do mesmo Código, mas aboliu o uso do termo "mulher honesta", absolutamente descabido diante dos posicionamentos e discussões mundiais acerca da igualdade e liberdade de gênero.

Tanto no caso da fila, em especial, a preferencial, quanto no caso do rapto, existem princípios norteadores que conduziram estas codificações. Um deles é o da Igualdade, que também utilizamos para exemplificar situação no common law, e que aqui retomamos para demonstrar que muito embora a palavra e o significado tenham pesos semelhantes nos distintos sistemas, fator que pode ser atribuído aos movimentos internacionais que se concretizam em tratados, suas manifestações são bastante diferentes. No common law pela reiteração da aplicabilidade do princípio frente ao caso concreto; no civil law pela existência de leis que garantam o exercício do princípio.

Sendo assim, o que dá força às discussões de cunho principiológico no sistema de civil law é o fato de estarem, os princípios, codificados. Em algum momento, dentro do ordenamento jurídico, será possível identificar os artigos nos quais os princípios estão alocados, o que pode implicar, inclusive, uma discussão acerca da validade dos e entre princípios, já que alguns estarão no topo da hierarquia, como os constitucionais, e outros estarão em patamares mais baixos por que codificados em legislações complementares ou ordinárias. 
Nesta perspectiva, o sistema jurídico do civil lawé formado pela consolidação hierarquizada do sistema de normas presente no ordenamento jurídico. Nas palavras de Nogueira (2013) "um edifício lógico e sistemático" (p.38).

Se o juiz do common law norte-americano não pode influenciar o processo na busca da verdade real e acaba tendo alguma liberdade quando se opta pelo julgamento singular, o juiz do civil law no sistema brasileiro pode influenciar o processo, mas no momento da tomada da decisão, fica preso às determinações legais.

Da mesma forma que se poderia, apressadamente, concluir que o juiz do common law, por atribuir significado à palavra, teria destaque no processo judicial, o que se mostrou irreal, também ao juiz do civil law, se poderia atribuir protagonismo por ter condições de influenciar o andamento do processo, fato que demonstraremos, não é de todo verdadeiro.

Embora possamos afirmar que os juízes brasileiros operem como condutores do processo legal, justificado entre outras coisas, por sua autonomia em determinar as provas necessárias à instrução processual (ASSIS, 2012), existem dois pontos a serem considerados e que delimitam a liberdade desta condução, quais sejam: o volume de trabalho e os fatos apresentados.

No que tange ao volume de trabalho Andrighi (1994) faz o seguinte destaque entre os sistemas jurídicos de civil lawe common law:

A análise comparativa minuciosa do nosso sistema procedimental civil com o desenvolvido nos EE.UU evidencia que, naquele país, a morosidade no andamento do processo não pode ser imputada ao Juiz, uma vez que a fase processual mais complexa e demorada, que é a instrutória, entre nós sempre dependente de vaga na pauta de audiências ou de realização de perícia técnica, não se desenvolve em juízo (p.4)

O fato de a busca pela verdade real não fazer parte das incumbências do juiz, contribui para a celeridade processual no sistema de common law (ANDRIGHI, 1999). De acordo com Paes e Mendes (2013) ainda que o Novo Código de Processo Civil tenha trazido mudanças que visem um trâmite mais célere, "não contempla uma solução em definitivo para a atual crise, haja vista ser este um problema que vai além da norma processual" (p. 781) reclamando uma revisão na própria estrutura da administração pública.

De acordo com a última publicação do Relatório da Justiça em Números (2015) do Conselho Nacional de Justiça, os dados gerais do Poder Judiciário demonstram que o ano de 2014 iniciou com um estoque de 70,8 milhões de processos, estimando que ao final do ano o número seria de 71,2 milhões de processos pendentes, já que o total de processos baixados foi menor do que os ingressados. Também de acordo com o documento, o congestionamento do Poder Judiciário foi de $71,4 \%$ no ano de 2014 , com aumento de 0,8 pontos percentuais em relação ao ano anterior, isso significa que de cada 100 processos que entram, apenas 30 são julgadas no tempo devido. A Justiça Estadual detém $70 \%$ dos casos novos e quase $81 \%$ do total de casos pendentes do Poder Judiciário. 
A carga de trabalho por magistrado no Poder Judiciário é de 6.521 processos nos primeiros graus de jurisdição, e de 3.305 nos segundos graus. Na Justiça Estadual a relação é de 7.520 e 2.878 processos, respectivamente, sendo que aproximadamente 69\% dos magistrados do Poder Judiciário, atuam nesta esfera (CONSELHO NACIONAL DE JUSTIÇA, 2015).

Não fosse o volume de trabalho a impossibilitar uma atuação protagonista do juiz frente aos processos que lhe são submetidos, há que se considerar ainda a apresentação dos fatos; que é um dos requisitos da petição inicial, de acordo com o artigo 319 do Novo Código de Processo Civil (BRASIL 2015).

Num processo judicial se tem, salvo parcas exceções, dois polos: autor e réu. Essas são as duas perspectivas que vão aparecer no processo dando condições ao juiz de tentar identificar uma narrativa de fatos não tendenciosa.

A sociedade não se faz de dicotomias, as relações sociais guardam as mais variadas complexidades quaisquer que sejam as matrizes de análise (TRIVIÑOS, 1987), complexidades estas que não surgem, por completo, num processo narrado por duas perspectivas. Se no sistema de common lawo antolho era colocado no juiz na fase da decisão, no civil law, o mesmo acessório é utilizado, mas numa fase distinta, qual seja, durante a busca pela verdade real, já que o juiz conhecerá apenas o universo que lhe for apresentado pelas partes, devendo determinar as provas dentro deste escopo pré-estabelecido.

Poder-se-ia afirmar que o chamamento de testemunhas, enquanto prerrogativa do juiz em reclamar as provas necessárias à instrução do processo, acabaria quebrando a suposta dicotomia presente nos discursos, ampliando o universo de atuação, todavia, "a prova testemunhal é a pior prova que existe" (MARTINS, 2010 p.336) "tendo sido a mais questionada de todas" (SILVA \& SILVA, 1998 p.46):

(...) as testemunhas contribuem com suas percepções sensoriais a respeito de tais fatos que interessam à causa e que não eram da cognição privada do juiz; ainda que o fossem, ao magistrado apenas seria lícito julgar segundo seus conhecimentos pessoais somente em casos extraordinários. Eis por que às testemunhas cabe reproduzir, perante o juiz, a realidade que captaram; mas o descrédito que se tem manifestado quanto a esse meio de prova reside, exatamente, na possibilidade de essa realidade ser subvertida, contrafeita, em virtude de certas regras de conveniência da própria testemunha ou da parte que a apresentou em juízo. Ninguém ignora, aliás, a existência de testemunhas profissionais, que tanto mal causam à honorabilidade e ao conteúdo ético do processo judiciário.(TEIXEIRA FILHO, 1997 p.300)

E quanto à decisão final no sistema de civil law? O que significa dizer que o juiz está preso às determinações legais? Em primeiro lugar, devemos destacar que, diferente do sistema de common law norteamericano em que é possível, na fase de decisão do direito civil, optar pelo julgamento singular ou pelo Júri, no civil law brasileiro não há opção. De acordo com a determinação do Código de Processo Penal (art. 74, \$1) (BRASIL, 1941) o Júri só se faz presente nos crimes contra a vida - homicídio, auxílio ao suicídio, infanticídio e aborto - (arts. 121 a 128 CP) (BRASI, 1940), as Varas Cíveis ficam por conta dos magistrados, salvo exceções de arbitragem (art. 3ㅇ $\left.\$ 1^{\circ} \mathrm{CPC}\right)$ (BRASIL, 2015). 
Em segundo lugar, mas nem por isso menos importante, o escopo da decisão do juiz no sistema de civil law brasileiro, foi estabelecido antes de qualquer condução processual na busca da verdade. Ocorre que, ao apresentar a petição inicial, além dos fatos, o autor, e o réu no contraditório, ou seja, nas respostas que lhe cabem diante da petição inicial a si dirigida, devem também apresentar os fundamentos jurídicos do pedido e suas especificações ${ }^{9}$ (art.319 CPC), bem como o próprio pedido.

O pedido é a forma como autor e/ou réu querem que o direito seja realizado. Depois de expor os fatos, os fundamentos jurídicos e seus fundamentos legais, há a necessidade de propor encaminhamentos ao juiz, ou seja, de propor formas de atingir o objetivo dos litigantes. Tendo esse caráter de propositura de efetivação dos direitos que, entendem as partes, foram desrespeitados ou ignorados, acompanham o pedido, enquanto características fundamentais, a necessidade de serem certos e determinados (arts. 322 e 324 CPC) (BRASIL, 2015); em outras palavras, é preciso que as partes tenham clareza absoluta do que desejam, e devem manifestar este desejo, já na petição inicial (NERY JÚNIOR, 2006).

Ainda que o juiz tivesse condições de conduzir o processo na busca da verdade real, independentemente do que descubra, estará preso aos pedidos que lhe foram feitos. Essa restrição não se baseia no simples fato de as partes apresentarem, de antemão, os pedidos, mas principalmente na proibição do non liquete na impossibilidade de decidir diferente do que foi solicitado.

De acordo com Assis (2012), a expressão latina non liquet trata-se do juramento de um juiz romano, de que o caso não estava claro e por consequência escusava-se em julgá-lo. Esta prerrogativa não pode ser reclamada pelo juiz no sistema de civil law brasileiro, e tal impedimento está regulamentado pelo artigo 140 do Novo Código de Processo Civil, que versa: $\mathrm{O}$ juiz não se exime de decidir sob a alegação de lacuna ou obscuridade do ordenamento jurídico (BRASIL, 2015).

Soma-se a isto a impossibilidade de decidir diferente do que foi pedido, fato declarado no artigo 141 do mesmo código (O juiz decidirá o mérito nos limites propostos pelas partes, sendo-lhe vedado conhecer de questões não suscitadas a cujo respeito a lei exige iniciativa da parte) e no artigo 492 (É vedado ao juiz proferir decisão de natureza diversa da pedida, bem como condenar a parte em quantidade superior ou em objeto diverso do que lhe foi demandado) (BRASIL, 2015).

Aqui é necessário fazer duas observações. A primeira delas é referente ao texto do artigo 141 mencionado anteriormente em que, além de não permitir ao juiz extrapolar os limites do pedido, também lhe é proibido considerar questões que não foram tratadas no processo, mas que talvez pudessem ter sido deduzidas pelo

\footnotetext{
${ }^{9}$ Os fundamentos jurídicos do pedido não devem ser confundidos com os fundamentos legais, estes são os artigos da legislação, as normas, que sustentam os argumentos; aquele é o motivo que justifica a propositura da ação judicial, seja baseado na lei ou nos princípios. Trata-se da conexão entre os fatos e o Direito, feito através dos fundamentos legais (VIANA, 2006).
} 
magistrado; fato que reforça nosso entendimento de que, muito embora o juiz possa conduzir o processo, seu escopo de atuação continua limitado pela arena criada pelas partes e pelos pedidos que fizeram:

Este dispositivo legal consagra a teoria da substanciação, segundo a qual, os fatos narrados influem na delimitação objetiva da demanda e consequentemente da sentença. Conforme lição de Nelson Nery Junior: "É o autor quem, na petição, fixa os limites da lide. É ele quem deduz pretensão em juízo. $\mathrm{O}$ réu, ao contestar, apenas se defende do pedido do autor, não deduzindo pretensão alguma. Quando reconvém, o réu se torna autor da reconvenção, fixando os limites da lide reconvencional na petição incial desta ação" (IMHOF \& REZENDE, 2015 p. 137).

A segunda observação é acerca da consequência de uma decisão que saia dos limites propostos. Neste caso o juiz terá decidido menos do que foi pedido (cita petita), mais do que foi pedido (ultra petita) ou diferente do que foi pedido (extra petita) (ASSIS, 2012); quando isto ocorre, as partes podem recorrer da decisão, vale dizer, podem pedir que ela seja reformulada. Tal pedido é feito através de um instrumento processual chamado Embargos de Declaração (art. 494 NCPC) (BRASIL, 2015).

Expostas todas estas considerações é possível afirmar que não se pode comparar as atuações dos juízes de cada sistema, sem considerações às suas especificidades realizando simples transposição de teorias para construir arcabouço teórico-metodológico acerca da análise das relações entre Poder Judiciário e políticas, pois ainda que se trate das Altas Cortes americanas e do Superior Tribunal de Justiça - STJ ou Supremo Tribunal Federal - STF, o caminho percorrido até eles e a forma como devem se pronunciar são extremamente distintas.

No mais, embora as altas cortes de ambos sistemas, sejam responsáveis pela manifestação do significado pertinente a uma palavra, como o reconhecimento da União Homoafetiva em que se atribuiu um significado mais amplo à palavra "casamento", quem tem participado das fases de elaboração e implementação de políticas no Brasil, são os primeiros graus de jurisdição. São as Varas com suas decisões monocráticas dos Juízes de Direito atingindo, no máximo, os Tribunais de Justiça, para uma decisão colegiada de 3 desembargadores em um recurso que, dificilmente, será encaminhado para o Superior Tribunal de Justiça - STJ ou para o Supremo Tribunal Federal - STF haja vista as especificidades do Recurso Especial e do Recurso Extraordinário (ASSIS, 2012).

Então, se o juiz não é protagonista, é coadjuvante de quem?

\section{PARÊNTESES}

Antes de definirmos quem são os comunicadores da norma, precisamos estabelecer alguns parâmetros conceituais, em especial, qual a diferença entre controle judicial, judicialização e ativismo judicial, bem como 
outras expressões possíveis diante dos cenários em que as políticas públicas se relacionam com o Poder Judiciário $^{10}$, vez que são fruto da atuação dos comunicadores da norma.

Para Appio (2009), qualquer relação que seja estabelecida entre o Judiciário e as políticas públicas deve nomear-se "controle judicial das políticas públicas":

Ao atuar em sede de controle das políticas públicas, o Poder Judiciário assume a função política de controle dos atos do Poder Legislativo e Executivo em face da Constituição Federal de 1988, seja no âmbito normativo, seja no âmbito administrativo, de forma a assegurar uma ampliação no debate democrático sobre as decisões que afetam todos os cidadãos (APPIO, 2009, p. 66).

Muito embora seja uma perspectiva bastante dialógica, Assis (2012) discorda do termo utilizado por Appio (2009) vez que o controle judicial está diretamente relacionado a atos meramente declaratórios, em que o Judiciário é convocado a manifestar-se de maneira bastante objetiva, determinando questões de legalidade/ilegalidade legitimidade/ilegitimidade e/ou constitucionalidade/inconstitucionalidade. Em outras palavras, esse tipo de atuação não visa solucionar problemas de implementação e/ou elaboração de políticas públicas, mas de direcioná-las, deixando-as, seja em termos legais ou de execução, alinhadas ao ordenamento jurídico.

O fato de um chefe do Poder Executivo não garantir a matrícula em idade escolar obrigatória e gratuita é inconstitucional. Ter a situação declarada como inconstitucional pelo Judiciário dá forças aos possíveis pedidos subsequentes que podem visar à solução da problemática - que é a efetuação da matrícula de um determinado indivíduo - mas não resolve o problema - a inexistência da devida quantidade de vagas escolares para educação obrigatória e gratuita -

A "judicialização" também é termo controverso, e que muitas vezes vem acompanhado de outros substantivos. Maciel e Koerner (2002), bem como Damasceno (2012), debatem, de forma mais aprofundada, a origem, a modificação e mutação do termo ao longo do tempo e em diferentes matrizes teórico-metodológicas. Nestes estudos, as mais marcantes são as de Tate e Vallinder (1995), que inauguram a discussão sobre a temática, e Vianna et. al. (1999). Aos quais acrescentaremos Oliveira (2005) e Assis (2012).

Para Tate e Vallinder (1995) “judicialização da política” se configura na substituição do poder de decisão dos Poderes Legislativo e Executivo pelo Judiciário. Mesmo que os autores ressaltem que a judicialização é um "fenômeno raro" (OLIVEIRA, 2005, p.562), na nossa exposição anterior notamos que podemos somar à raridade do ato, a limitação do mesmo, haja vista não participarem, os juízes, da busca pela verdade real. No mais, veremos adiante que esta compreensão se aproxima mais do ativismo judicial do que das outras formas de compreender judicialização.

\footnotetext{
${ }^{10}$ Ainda que não seja objetivo deste artigo, é importante salientar que o contexto que envolve essa discussão conceitual parte do pressuposto de que existe um limite a ser estabelecido na relação de e entre Poderes (DAMASCENO, 2012; GARGARELA, 2014; ASSIS, 2015), já que de outra feita, uma compreensão bastante distinta seria construída.
} 
Já para Vianna et. al. (1999) a judicialização é a capacidade de o Judiciário funcionar como um árbitro na solução de conflitos entre os Poderes e a sociedade civil, atuação que está para a além do controle judicial, mas que não promove protagonismo nas fases de elaboração e implementação das políticas.

Oliveira (2005) entende por judicialização da política "a utilização de procedimentos judiciais para a resolução de conflitos de ordem política, tais como controvérsias a respeito de normas, resoluções e políticas públicas em geral” (p. 559), e por judicialização "a capacidade de o Judiciário intervir em políticas públicas, interferindo ou alterando, em alguns casos, o status quo vigente" (p.559). A autora engloba o controle judicial na judicialização das políticas, o que não deixa de ser verdadeiro naquilo que ela compreende sobre judicialização.

Como uma ramificação de Vianna et. al. (1999), Assis (2012) entende que a judicialização é a provocação do Poder Judiciário por parte daqueles que desejam discutir a política, independentemente se o resultado trará modificações ao status quo. Esse posicionamento se dá por defender, Assis (2012), diferente de Van Meter e Van Horn (1993), que o Poder Judiciário participa apenas da fase de avaliação da política, e não das demais relacionadas à elaboração e à implementação.

Nesse sentido, Assis (2012) aponta existir dois tipos de judicialização, a saber, dentro dos limites da atuação do Poder Judiciário e por decisão liminar ou por ignorar pedido de controle judicial:

A judicialização dentro dos limites de atuação do Poder Judiciário pode ser entendida (...) como a atuação do juiz frente a pedidos que não exigem um posicionamento ativista, ou seja, que não the fazer substituir o legislador ou o tomador de decisões (...) a Judicialização por decisão liminar seria a concessão dos pedidos do autor da ação, sem que o juiz tenha conhecimento das considerações e pedidos do réu (...) correndo o risco de ignorar pedido de controle judicial a ser apresentado como opção pela outra parte; vale dizer, o juiz opta por uma atitude ativista sem ter conhecimento do que a outra parte proporia (ASSIS, 2015 p.206-207).

O ativismo judicial talvez seja o termo que menos provoca discordâncias, se trata de uma atuação protagonista do Poder Judiciário frente à judicialização - no sentido de Vianna et. al. (1999) e Assis (2012) - da política. Qualquer situação em que o Poder Judiciário participe ativamente, e não como arbitrário, das fases de elaboração e implementação de políticas públicas, seja numa perspectiva de etapas ou ciclo, é ativismo judicial. Embora o termo seja de amplo uso, o que separa os teóricos, é defender ou não a legitimidade de uma atuação ativista. Daí entendermos que a visão de Tate e Vallinder (1995) se aproxima mais do ativismo, assim como o posicionamento de Oliveira (2005).

Todavia, há que se apontar, tendo como base não só o que foi discutido até o momento, mas em especial a citação anterior, de que o ativismo, ao menos no Brasil, não é essencialmente judicial (ASSIS, 2015) ${ }^{11}$; afora a

\footnotetext{
${ }^{11}$ No sistema de common law norte-americano, o ativismo pode ser considerado essencialmente judicial, haja vista terem seus juízes um grau de liberdade muito maior do que os juízes brasileiros. Ainda que a limitação exista por não participarem da busca pela verdade, não estão amarrados aos pedidos certos e determinados.
} 
decisão liminar, ou que seja cita, extra ou ultra petita, todas as outras possibilidades são criadas ao juiz, e não de uma atuação protagonista de sua parte.

Note, considerando também o apresentado no item anterior, de que são nas petições iniciais, com seus objetos de ações que se determinam: a) se haverá judicialização da política, vale dizer, se o objeto da ação é a discussão de uma política pública; b) se a judicialização é em sede de controle judicial, o que reclamaria um posicionamento declaratório do Judiciário sem entrar nos pormenores da discussão da política; c) se a judicialização terá caráter ativista e se este ativismo virá do juiz ou será proposto a ele.

Com o palco montado, contemplem: eis o comunicador da norma!

\section{MAS AFINAL, QUEM É O COMUNICADOR DA NORMA?}

O comunicador da norma, nada mais é do que o jurista, cada qual representando as suas partes, responsável por levar ao juiz, por meio das petições de diversas naturezas (ações civis públicas, mandados de segunda ou injunção, recursos, entre outros), o conhecimento dos fatos, dos fundamentos jurídicos e legais e dos pedidos.

Concebemos que é fundamental distinguir o comunicador da norma, do comunicador normativo de Ferraz Júnior (2013), diretamente relacionado a uma discussão de discurso normativo, na perspectiva da pragmática. Com certeza há a possibilidade de problematizar a relação entre estas duas figuras, mas deve estar claro que não são sinônimos, tampouco trata-se de uma questão meramente semântica.

A tradução dos fatos e sua relação com as fundamentações legais e jurídicas vislumbrando um pedido certo e determinado é de responsabilidade do comunicador da norma. Ele dará o tom do processo, identificando condições de judicialização da política, seja por controle judicial, por ativismo ou dentro dos limites de atuação do Poder Judiciário.

No sistema de common law, tem a responsabilidade de concertar a busca pela verdade real dentro das perspectivas daquele que representa, delimitando a arena de atuação do (s) julgador (es), bem como de avaliar a melhor opção para decisão final, seja por Júri ou Julgamento singular, a entender quem será mais suscetível à sua sedução frente ao comunicador da norma da outra parte.

Dadas as condições de trabalho do magistrado, anteriormente apresentadas com foco na relação entre a quantidade de processos e de juízes, e sua dependência diante dos fatos apresentados, no sistema de civil law, a responsabilidade do comunicador da norma é ainda maior, vez que se responsabiliza tanto por determinar a arena do discovery, quanto da decisão final com a apresentação dos pedidos.

Mas, não podemos nos iludir quando se trata de comunicadores da norma do Ministério Público ou da Defensoria Pública, vez que a consideração acerca da carga de trabalho também lhes cabe, o que prejudica todo o 
processo de busca pela verdade real. Num caso que envolva, de um lado, um promotor e, de outro, um defensor e na mediação um juiz, como ficará a dedicação devida à busca da verdade real?

Consideremos, também, a possibilidade de o comunicador da norma realizar a judicialização sem cumprir com os requisitos processuais mínimos necessários ao andamento do processo e ter uma resposta com resolução do conflito sem discussão do mérito, ainda que tenha tido todos os cuidados para reclamar uma atuação do Judiciário dentro de seus limites, precisa estar atento às questões formais.

Quando se trata de discutir políticas públicas junto ao Poder Judiciário o comunicador da norma, com base na análise tecida, precisa entender-se como jurista e não como operador do direito. Entender-se como jurista não lhe garante um conhecimento aprofundado sobre cada uma das questões sociais como educação, moradia, saneamento, saúde, meio ambiente, segurança, entre outros, mas lhe dá condições de transitar pelos conhecimentos de ciências políticas, ciências sociais, inclusive para diferenciar a problemática do problema (VILLANUEVA, 1996).

Entender-se jurista é, também, avaliar se a judicialização é a opção mais adequada, tendo em vista a possibilidade de, no Ministério Público, em particular, termos o que SILVA (2001) nomeou "promotor de fato", quando da concertação intersetorial na busca da solução de um problema público.

Um exemplo que podemos trazer está na área da Educação, onde um dos processos mais comuns de judicialização de políticas públicas são as buscas por vagas escolares na etapa da Educação Infantil (ASSIS, 2012). Entendemos que por falta desta compreensão da importância do papel protagonista do comunicador da norma, bem como por não se entender jurista no mais amplo sentido, cumulado com a alta carga de trabalho, atacam a problemática - a falta de vagas escolares para cada uma das crianças de determinado município - realizando pedidos que culminam no ativismo judicial - colocar a criança dentro da escola -, ao invés de judicializar o problema - a falta, generalizada, de vagas - propondo pedidos que permitam a atuação do Judiciário dentro de seus limites - como a construção de escolas e contratação de profissionais.

Contudo, para entender-se jurista, é necessário que a sua formação seja discutida. Que seu espaço de atuação seja visto como parte da sociedade, e não como um ente distante onde só se tratam problemas ao invés de soluções.

\section{E AGORA, JOSÉ?}

A declaração da morte de Deus, conforme iniciamos essas reflexões na perspectiva de Friedrich Nietzsche, não significa sua degenerescência e, no caso do juiz, o anúncio de sua morte não diz respeito ao seu aniquilamento, mas, justamente, a hipótese de percepção desse ator como um dos protagonistas das decisões judiciais. Em outros termos, reconhecer os limites do magistrado significa, em última instância, percebê-lo como 
um novo ator, a partir de novos e outros fatos, da mesma forma que a morte de Deus para Nietzsche significa sua crítica à verdade, ao absoluto, inaugurando a fase da interpretação do conhecimento.

O juiz não deixou de estar lá, mas percebe-se, agora, que além de não estar só, não é figura central, pois totalmente dependente daquele com quem dialoga. Ao juiz só é permitido ver e ouvir, se há quem lhe mostre ou lhe diga algo.

Embora só tenhamos revelado a identidade do comunicador da norma ao final do texto, ele estava presente em todo o momento. Não é possível uma discussão de diferenças entre sistemas jurídicos, sem pensar em quem movimenta estes sistemas; bem como não é possível pensar em decisões, sem considerar quem apresenta as situações que carecem de decisão. $\mathrm{O}$ mesmo vale para a determinação da natureza jurídica de cada processo. O comunicador da norma cria, nomeia e conduz, o juiz certifica ou não.

Como foi que deixamos - ou por que deixamos - passar esse protagonismo tão despercebido? E como pretendemos, nós - acadêmicos - junto com eles - comunicadores da norma - pensar soluções conjuntas para problemas públicos?

Neste contexto, por uma perspectiva em que o protagonista está muito mais próximo da sociedade, a intersetorialização se torna ação cada vez mais possível, sendo a palavra de ordem para evitar a judicialização desnecessária ou garantir uma judicialização dentro dos limites de atuação do Judiciário.

\section{BEHOLD! THE NORM COMMUNICATOR.}

\section{Abstract}

The objective of this article is to problematize the myth of the judge as a major player in the judicialization process of public policies, to present the norm communicator as real main actor. Through compared problematization on both civil and common law systems and the magistrate's role in these systems, followed by the conceptualization of the terms "judicial control", "judicialization" and "judicial activism" to demonstrate that its characteristics are predetermined in initials, we demonstrate the supporting role of the judge and the high level of the norm communicator's responsibility, whom we conceptualize and define its role, especially when it comes to the discussion of public issues with the judiciary. Without intending to propose solutions, we concluded with a reflection on the silence around this real protagonism.

Keywords: Judicialization; Norm Communicator; Public Policy; Legal Systems

\section{REFERÊNCIAS BIBLIOGRÁFICAS}

ANDRIGHI, Fátima Nancy. Estrutura e dinâmica do poder judiciário norte-americano : aspectos da composição judicial e extrajudicial dos litígios. In: TEIXEIRA, Salvio de Figueiredo. O Judiciário e a constituição. São Paulo: Saraiva, 1994. 
APPIO, Eduardo. Controle Judicial das Políticas Públicas no Brasil. Curitiba: Juruá, 2009.

ASSIS, Ana Elisa Spaolonzi Queiroz. Direito à Educação e Diálogo entre Poderes. Tese de Doutorado. Faculdade de Educação, UNICAMP, 2012.

Judicialização de Avaliações em larga escala: breves considerações. In: JEFFREY, Débora Cristina.

Política e Avaliação Educacional: interfaces com a espitemologia. Curitiba, PR: CRV, 2015.

BRASIL. Código de Processo Civil. Lei n. ${ }^{\circ} 13.105$ de 2015. Disponível em: http://www.planalto.gov.br/ccivil_03/_ato2015-2018/2015/lei/113105.htm Acesso em: 11 Mar.2016.

Código de Processo Penal. Decreto Lei n. ${ }^{\circ} 3.689$ de 1941. Disponível em: http://www.planalto.gov.br/ccivil_03/Decreto-Lei/Del3689.htm Acesso em: 11 Mar.2016.

Código Penal. Decreto Lei n. ${ }^{\circ} 2.848$ de 1940. Disponível em: http://www.planalto.gov.br/ccivil_03/decreto-lei/Del2848compilado.htm Acesso em: 11 Mar. 2016.

Declaração dos Direitos do Homem e do Cidadão de 1789. Disponível em: < http://pfdc.pgr.mpf.gov.br/atuacao-e-conteudos-de-apoio/legislacao/direitos-

humanos/declar_dir_homem_cidadao.pdf>.Acesso em: 11 Mar 2016.

Declaração Universal dos direitos humanos 1948. Disponível em: <http://portal.mj.gov.br/sedh/ct/legis_intern/ddh_bib_inter_universal.htm>.Acesso em: 11 Mar 2016.

CEPEDA RODRIGUEZ, Emerson Harvey. Corte Constitucional y conflicto armado. Control de políticas sociales en el marco del conflicto en Colombia. In: Rev. Fac. Derecho Cienc. Polit. - Univ. Pontif. Bolivar., Medellín , v. 42, n. 117, Julho 2012 . Disponível em: <http:/ /www.scielo.org.co/scielo.php?script=sci_arttext\&pid=S0120-8862012000200005\&lng=en\&nrm=iso>. Acesso em: 11 Mar. 2016.

CONSELHO NACIONAL DE JUSTIÇA. Relatório Justiça em Números 2015: ano base 2014. Brasília, DF: CNJ, 2015.

DAMASCENO, J.B. A crença no poder jurisdicional do Estado: judicialização das relações sociais e politização do Judiciário. In: Quaestio Iuris: Rio de Janeiro, RJ vol.05, no 01, 2012 pp. 300-341. Disponível em: http:/ /www.epublicacoes.uerj.br/index.php/quaestioiuris/article/view/9870/7732. Acesso em: 11 Mar. 2016.

DAVID, René. Os grandes sistemas do direito contemporâneo. São Paulo: Martins Fonte, 1996.

DELEUZE, Giles. GUATTARI, Félix. O anti-édipo: capitalismo e esquizofrenia. São Pau, SP: Editora 34, 2010.

FERRAZ JÚNIOR, Tércio Sampaio. Introdução ao estudo do Direito: técnica, decisão, dominação. $7^{a}$ ed. São Paulo: Atlas, 2013.

GARGARELLA, Roberto. (Org.) Por una justicia dialógica: El Poder Judicial como promotor de la deliberación democrática. Buenos Aires, Argentina: Siglo Veintiuno Editores, 2014.

HOUAISS, Antonio; VILLAR, Mauro de Salles; FRANCO, Afonso Arinos de Melo. Dicionário Houaiss da língua portuguesa. Rio de Janeiro: Objetiva, 2001.

IMHOF, Cristiano. REZENDE, Bertha Steckert. Novo Código de Processo Civil Comentado. Rio de Janeiro, RJ: Lumen Juris, 2015. 
KOERNER, Andrei. Ativismo Judicial?: Jurisprudência constitucional e política no STF pós-88. In: Novos estudos - CEBRAP, São Paulo, n. 96, p. 69-85, Julho 2013 . Disponível em: $<$ http://www.scielo.br/scielo.php?script=sci_arttext\&pid=S0101-33002013000200006\&lng=en\&nrm=iso $>$. Acesso em: 11 Mar. 2016.

MACIEL, Débora Alves e KOERNER, Andrei. Sentidos da judicialização da política: duas análises. In: Lua Nova no 57, 2002. Disponível em: http://www.scielo.br/pdf/ln/n57/a06n57 Acesso em: 11 Mar. 2016.

MARTINS, Sergio Pinto. Direito processual do trabalho. 30ª ed. São Paulo: Atlas, 2010.

MERRYMAN, John Henry, PÉREZ-PERDOMO, Rogelio. A tradição da civil Law - uma introdução aos sistemas jurídicos da Europa e da América Latina. Porto Alegre: Sérgio Antonio Fabris Editor, 2009.

METER, Donald Van; HORN, Carl Van. El proceso de implementación de las políticas: un marco conceptual. In: VILLANUEVA, L. A. La implementación de las políticas. Ciudad Del Mexico: Editorial Porrúa, 1993.

NERY JUNIOR, Nelson. Código de Processo Civil Comentado e Legislação Extravagante. São Paulo: Revista dos Tribunais, 2006.

NIETZSCHE, Friedrich. Die fröhliche Wissenschaft: La gaya scienza. Berlin: Goldmann, 1999.

A Gaia Ciência. Trad. Paulo César de Souza. São Paulo: Cia das Letras, 2001.

NOGUEIRA, Gustavo Santana. Precedentes vinculantes no direito comparado e brasileiro. 2aed. Salvador, BA: Editora JusPODIVM, 2013.

OLIVEIRA, Vanessa Elias. Judiciário e privatizações no Brasil: existe uma judicialização da política? In: Revista de Ciências Sociais. Rio de Janeiro, v. 48, n. 3, p.559-587, jul./set. 2005. Disponível em: <http://www.scielo.br/pdf/dados/v48n3/a04v48n3.pdf>. Acesso em: 11 Mar. 2016.

PAES, Maria Luísa Coelho; MENDES, Marisa Schmitt Siqueira. A morosidade do poder judiciário brasileiro e as modificações do novo CPC com relação a duração razoável do processo. In: Revista Eletrônica de Iniciação Científica. Itajaí, Centro de Ciências Sociais e Jurídicas da UNIVALI. v. 4, n.3, p. 781-799, 3º Trimestre de 2013. Disponível em: www.univali.br/ricc. Acesso em: 11 Mar. 2016.

RÁO, Vicente. O Direito e a Vida dos Direitos. São Paulo: Editora Revista Dos Tribunais, 1999.

REALE, Miguel. Filosofia do Direito. São Paulo: Saraiva, 2002.

RUTKOWSKI, Emília Wanda. Et al. Caixa de Ferramentas de Metodologias de Concertação para qualificação profissional. In: Revista da ABET. São Paulo, SP v.IX n.2, p.32-52, maio 2010. Disponível em: http://periodicos.ufpb.br/ojs/index.php/abet/article/view/15496/8859 Acesso em: 11 Mar. 2016.

SILVA, Justino Adriano Farias da; SILVA, Agathe Elsa Schmidt da. O problema perceptivo no testemunho judicial. In: Estudos Jurídicos, São Leopoldo, v. 31, n. 82. 1998.

TATE, Neal; VALLINDER, Torbjorn. The Global Expansion of Judicial Power. New York: New York University Press, 1995.

TEIXEIRA FILHO, Manoel Antonio. A prova no processo do trabalho. 7a ed. rev. e ampl. São Paulo: LTr, 1997. vol.10, no. 01, Rio de Janeiro, 2017. pp.241-257 256 
TRIVIÑOS, Augusto N. S.. Introdução à pesquisa em ciências sociais: a pesquisa qualitativa em educação. São Paulo: Atlas, 1987.

VIANA, Joseval Martins. Curso Completo de Processo Civil. São Paulo: Joares de Oliveira, 2006.

VIANNA, Luiz Werneck, Et. Al. A judicialização da política e das relações sociais no Brasil. Rio de Janeiro: Editora Revan, 1999.

VILLANUEVA, Luis Aguilar (Org.). La hechura de las políticas. Ciudad Del Mexico: Editorial Porrúa, 1996.

Trabalho enviado em 13 de julho de 2016.

Aceito em 10 de outubro de 2016. 